\title{
LOAN PAYMENT AND RENEGOTIATION: THE ROLE OF THE LIQUIDATION VALUE
}

This paper analyzes a model of bank loan repayment as the signalling game. The model shows that under asymmetric information a borrower reaches for renegotiation and debt forgiveness to a greater extent than is required by the return of the venture financed with the loan. In the equilibrium, the borrower pays the lesser of: an amount equal to the liquidation value or the amount of payment specified in the credit agreement. The loan contract induces strategic default and leniency of the bank on the equilibrium path. To offset the impact of the renegotiation options, the interest rate specified in the credit agreement should ex ante take into account the liquidation value of the borrower's assets. The paper also proposes an example of the utilisation of our theoretical model and the Monte Carlo method to determine the loan interest rate for a commercial loan.

Keywords: bank loan, debt, credit agreement, interest rate, liquidation value, game theory

JEL Classifications: C72, D86, G17, G21, G33

DOI: 10.15611 /aoe.2018.1.10

\section{INTRODUCTION}

Bank credit is one of the most important sources of financing of the economy. What distinguishes it from other forms of foreign capital is the possibility of debt renegotiation in cases of business failure. The idea of debt restructuring is inherent in banking practices and is designed to allow the survival of borrowers in temporary situations of economic hardship, so that later they can continue to operate and pay off debts.

Roberts and Sufi (2009), analyzing the cases of debt renegotiations of U.S. public companies, found that over $90 \%$ of long-term credit agreements are renegotiated before maturity, and that renegotiation is rarely the result of financial difficulties or the bankruptcy of the debtor. Gilson et al. (1990) found that a half of borrowers facing severe financial difficulties restructured debt on an informal basis as part of the renegotiation with creditors without the benefit of formal legal proceedings. Moreover, Davydenko (2012) found that about $70 \%$ of defaulting firms are not liquidated.

The bank, taking a decision on the restructuring of the debt, does not fully know the true financial condition of the borrower and is not able to assess its

\footnotetext{
* Faculty of Management, AGH University of Science and Technology.
} 
prospects for development. A detailed examination of the performance of the borrower would involve very high costs (audit, expertise, etc.) ${ }^{1}$. Such restrictions can lead to the borrower simulating his/her financial difficulty or lower return on investment than it is in reality. However, the threat of taking over collateral is an incentive for a borrower to repay the loan. Thus, collateral is the second fundamental factor of the credit agreements, in addition to restructuring.

The issue of debt renegotiation and the role of collateral was analyzed theoretically by many authors, for example: Barro (1976), Bester (1985 and 1994), Besanko and Thakor (1987), Thakor and Wilson (1995), Gorton and Kahne (2000), Coco (2000), Lacker (2001), Niinimaki (2011). The threat of loss of collateral is the self-selection risk mechanism for borrowers, and the incentive to repay the loan (Bester 1985). Less risky borrowers choose a contract with lower interest rates, but with collateral, as opposed to the more risky ones who prefer a higher interest rate in exchange for not having to pledge collateral, but to make it so the value of the collateral must not be correlated with the returns on investment projects undertaken by the borrower (Niinimaki 2011).

Collateral, however, does not play a major role as a tool for the selection of potential borrowers, but it is primarily an incentive to repay the loan after the contract (Cooco 2000). The high costs of monitoring the borrower's returns may induce the debtor to take over all or part of the return on the project for his/her own benefit instead of repaying the loan depending on the relationship of return on the project with the value of the collateral (Hart and Moor 1998; Barro 1976). This approach involves the role of collateral with the theory of incomplete contracts in which the opportunity to renegotiate the original agreement is essential.

The possibility of renegotiation induces a borrower to rollover risk on the lender. The theory of incomplete contracts suggests that the borrower seeks to renegotiate the credit agreement or not to pay if, after considering the possible actions of the bank and depending on the liquidation value of collateral, it is advantageous to borrowers. This idea is presented, among others, in the research of: Aghion and Bolton (1992), Bester (1994), Hart and Moor (1994 and 1998), Gorton and Kahne (2000), Bolton and Scharfstein (1996), and Lacker (2001). In particular, the work of Gorton and Kahn (2000) shows that in the process of renegotiation, the amount of loan

\footnotetext{
${ }^{1}$ Analysis of the impact of costs of verification of project returns on the shape of the credit agreement became the foundation of Costly State Verification models (see Gale and Hellwig 1985; a review of models see. e.g. Attar and Campioni 2003).
} 
repayment may not be the linear and continuous function of value and risk of collateral. The bank, under certain conditions, can reduce the amount of payment to avoid moral hazard and the increase of the risk of the borrower's assets, but where this is not possible, the bank requires a higher payment from the borrower.

According to the research of: Aghion and Bolton (1992), Hart and Moor (1994 and 1998) and Bolton and Scharfstein (1996), the liquidation value of collateral determines not only the amounts recovered by the bank in the absence of the loan repayment but also affects the results of the renegotiation of the debt. This is due to the fact that the threat of taking over assets is an incentive for the borrower to avoid default, thus the liquidation value determines the ex post amount of loan repayment. When the liquidation value is low, then bargaining power of the borrower increases and reduces the amount of debt repaid.

The main objective of this paper is to analyze the model of loan repayment as the signalling game in which the expected ex ante renegotiation depending on the liquidation value of the borrower's assets plays a key role. The behaviour of the borrower and the amount of debt repaid at the time of repayment are the factors influencing the terms and conditions of the credit agreement at the stage of the contract signing, including the loan interest rate.

The model incorporates a number of components of the lender-borrower relationship. First, the model relates to issues of the role of collateral and the loan renegotiation studied by Bester (1985 and 1994). Second, the voluntary repayment of debt is assumed in the model. The borrower determines the amount of repayment alone, trying to avoid enforcement of the debt by execution. This approach refers to the models of Krasa and Villamil (2000) and Krasa, Sharma and Villamil (2005). The main difference with respect to these models is to express the return on the investment project as a continuous random variable, which allows for the practical use of the model to determine the loan rate by a bank. Moreover, unlike the model of Bester (1994), collateral is treated as productive assets rather than as a separate asset of the borrower. In the event of insolvency, the debtor's collateral is seized by the bank along with the enterprise. Our assumptions are also consistent with findings of Hvide and Leite (2010) in which default is not synonymous with bankruptcy, unlike in Gale and Hellwig (1985), as a result of strategic default and renegotiation.

The rest of the article is organized as follows: the second section presents the assumptions of the model and the analysis of equilibrium conditions for the 
model. The third section analyzes the impact of the debt repayment function on the loan rate at the time of writing a credit agreement. In the fourth section an example of pricing of a loan using a theoretical model and the Monte Carlo simulation is presented. The article ends with a brief summary.

\section{MODEL OF LOAN REPAYMENT}

Consider an economy with two risk neutral agents: an entrepreneur and a bank (their subscripts are, respectively, $E$ and $B$ ). The bank operates in a competitive credit market, and the cost of raising capital for the bank is $r_{B}$. Assume first that the entrepreneur signed a credit agreement with the bank to finance a venture. The credit agreement $\left(I, R_{1}, C\right)$ with the bank is a triplet that a given amount of the loan $I$ determines the amount of repayment $R_{1}$ and collateral $C$. The loan repayment $R_{1}$ is independent of the project outcome, thus we assume that the credit agreement is a standard debt contract (SDC) with collateral. The standard debt contract is a contract in which a borrower agrees to pay a fixed amount, and non-payment allows the bank to seize the borrower's assets being the output of the project ${ }^{2}$. We assume additionally that collateral is indivisible because it is a production technology.

The return of the project is a random variable $Y$ with realizations $y \in[0, \bar{y}] \subset \mathbb{R}_{+}$, with continuous and differentiable distribution function $F(y)$ and continuous density $f(y)$. This return of the project is observable without costs only by the entrepreneur, which is known to both agents. Agents have common knowledge of the prior beliefs $\beta(\cdot)$ on the set of possible realizations $Y$, where $\beta(y)>0$. Beliefs $\beta(y)$ have a density $f(y)^{3}$.

In the case of default, the entrepreneur can turn to the bank for a debt restructuring involving the cancellation of the debt. The bank may restructure the debt or seize the collateral together with the venture. The value of collateral is lower to the bank than to the borrower because of the cost of acquisition and disposal, and is $b C$, where $0 \leq b<1$. Similarly, the acquisition of the venture and possible management generates significant costs, thus the value of the project output for the bank is $a Y$, where $0 \leq a<1$.

The entrepreneur, signing a loan contract with the bank, calculates in advance the possibility of renegotiation ${ }^{4}$. The borrower is aware that the

\footnotetext{
${ }^{2}$ Cf. Gale and Hellwig (1985) or Krasa and Villamil (2000).

3 The possibility of the borrower's and the lender's heterogeneous beliefs on the project returns, see for example: Carlier and Reneou (2005).

${ }^{4}$ The value of renegotiation of the loan is calculated, for example, in the model of Thakor and Wilson (1995).
} 
bank learned of his/her default, and would be inclined to renegotiate the debt, provided that the amount of debt outstanding after the redemption of its parts exceeds the value of collateral and the venture from the bank's point of view.

Assume further that the $C \leq R_{1}$, which means that the bank has no collateral exceeding the value of the loan. The outcome of the project $Y$ can be thought of as the present value of discounted cash flows $C F_{t}$ generated by the project in the subsequent periods of time in the future, where $C F_{t}$ is random variable. We have:

$$
y=\sum_{t=1}^{\infty} \frac{C F_{t}}{\left(1+d_{t}\right)^{t}},
$$

where:

$d_{t}-$ discount rate in period $t$.

In addition, the credit agreement may be treated in a certain sense as a doubly periodic contract, as in Hart and Moor (1998). In the second period, the borrower, getting to know the profitability of the investment project, decides whether to repay the loan and at what rate, or transfer control of its assets to the bank. The value of the collateral for the bank $b C$ is equivalent to the liquidation value of the assets of the borrower $L$ at the beginning of the second period in that model.

After signing the credit agreement $\left(I, R_{1}, C\right)$ in period $t=0$, the game of loan repayment is as follows.

1. In the first period $t=1$, nature selects return on the project $y$.

2. In the next period $t=2$, the entrepreneur observes the project outcome. Knowing the return y the entrepreneur decides to make voluntary payment $v \in[0, \bar{y}] \subset \mathbb{R}_{+}$, which may, but need not, be equal to the payment $R_{1}$ required by the credit agreement, if only $y \geq R_{1}$. If $v<R_{1}$, then the entrepreneur has to declare default and counts on debt forgiveness $x=R_{1}-v$. The pure strategy of the entrepreneur is a payment $v$ made after observing the return $y$. The decision on payment $v$ can no longer be changed later (due to the inclusion of relevant data in the financial records).

3 . In the last period $t=3$, the lender by observing the proposed $v$, but not knowing the true state of nature, determines, when $v<R_{1}$, whether to restructure debt and offer the new credit agreement $(I, v, C)$, or whether to seize the project with collateral. If $v=R_{1}$, the bank accepts payment in accordance with the credit agreement. The behavioural strategy of the lender 
$\sigma_{B}$ is the probability of the loan restructuring and acceptance of payment $v$. The strategy $\sigma_{B}=1$ means acceptance of the payment $v$, moreover, if $v<R_{1}$, means a new contract and partial cancellation of the debt on amount $x$. While $\sigma_{B}=0$ means the liquidation of the loan.

The model setup is summarized in Figure 1.

\begin{tabular}{|c|c|c|c|}
\hline$t=0$ & $t=1$ & $t=2$ & $t=3$ \\
\hline $\begin{array}{l}\beta(y) \text { - prior belief on the } \\
\text { project returns, } \\
\text { Credit agreement }\left(I, R_{1}, C\right) \text { : } \\
I-\text { amount of loan, } \\
R_{1} \text { - amount of repayment, } \\
C \text { - value of collateral. }\end{array}$ & $\begin{array}{l}y \text {-project } \\
\text { outcome. }\end{array}$ & $\begin{array}{l}v \text { - signal - } \\
\text { voluntary } \\
\text { repayment of the } \\
\text { entrepreneur. }\end{array}$ & $\begin{array}{l}\beta(y \mid v) \text { - updated } \\
\text { belief of the bank on } \\
\text { the project outcome, } \\
\sigma_{B}-\text { strategy of the } \\
\text { bank - acceptance or } \\
\text { liquidation. }\end{array}$ \\
\hline
\end{tabular}

Figure 1. Timing of the game

Source: author's own.

Let us define the profits of the bank in the case of seizing the borrower's assets as follows.

Definition 1. Value $L(y)=a y+b C+\bar{u}$ is called the liquidation value of the loan.

Reservation value $\bar{u}$ is the value of the acquisition of borrower's assets ${ }^{5}$, the lack of need for restructuring the loan and the long-term monitoring of the process, and the possibility of the release of reserves for non-performing loans and writing-off accounts receivable as lost. Reservation value may also be negative, depending on the particular case. Companies in emerging industries, promising further cooperation with the bank and paying off another loan, can be subjected to restructuring because of the future benefits for the bank ${ }^{6}$.

Expected payoff of the entrepreneur $E \pi_{E}$ and the bank $E \pi_{B}$ for a pair of strategies $v$ and $\sigma_{B}$ after observing by the entrepreneur the return $y$ are, respectively,

\footnotetext{
${ }^{5}$ Franks and Sussman (2005) show that banks tend to take over valuable assets regardless of the efforts of borrowers engaged in debt restructuring.

${ }^{6}$ This is the problem of so-called relationship lending - an important role in this was played by the model of Rajan (1992), see overview of the models: Boot (2000), and examples of empirical studies can be found in the work of: Petersen and Rajan (1994), Degryse (2000), Bharath et al. (2007).
} 


$$
E_{v, \sigma_{B}} \pi_{E}\left(y, v, \sigma_{B}\right)=\sigma_{B}(y-v)-\left(1-\sigma_{B}\right) C
$$

and

$$
E_{\sigma_{B}} \pi_{B}\left(y, v, \sigma_{B}\right)=\int_{y \in Y} \beta(y \mid v)\left[\sigma_{B} v+\left(1-\sigma_{B}\right) L(y)\right] d y
$$

Definition 2. Strategy profile $v, \sigma_{B}$ of the entrepreneur and the bank along with beliefs $\beta(y), \beta(y \mid v)$ is a perfect Bayesian equilibrium if and only if

(i) $v \in Y$ maximizes the expected payoff $E_{v, \sigma_{B}} \pi_{E}\left(y, v, \sigma_{B}\right)$ for each $y$.

(ii) $\sigma_{B} \in \Sigma_{B}$ maximizes the expected payoff $E_{\sigma_{B}} \pi_{B}\left(y, v, \sigma_{B}\right)$ for each $v$.

(iii) $\beta(y \mid v)$ is derived from $\beta(y)$ using Bayes' rule, if it is possible.

Otherwise $\beta(y \mid v)$ is any probability on $\{y \in Y \mid y \geq v\}$.

Conditions (i) and (ii) impose a requirement that each strategy was a perfect Bayesian equilibrium for each subgame with some beliefs. The return on the project $y$ is the same as the type of entrepreneur in the game. Condition (iii) specifies how to update beliefs after observing the declared amount of repayment $v$ using Bayes' rule.

The entrepreneur, knowing the return $y$ and deciding to make a payment $v$ has to solve the following problem.

Problem 1. At time $t=2$ find $v$ and $\sigma_{B}$ to solve the following optimization problem

$$
\max _{v, \sigma_{B}} E_{v, \sigma_{B}} \pi_{E}\left(y, v, \sigma_{B}\right)
$$

subject to

$$
\begin{gathered}
E_{\sigma_{B}} \pi_{B}\left(y, v, \sigma_{B}\right) \geq \int_{y \in Y} \beta(y \mid v) \min \left\{R_{1}, L(y)\right\} d y \text { for each } y, \\
\text { having } \beta(y \mid v)>0, \\
0 \leq v \leq y \text { and } v \leq R_{1} \text { for all } y, \\
v, \sigma_{B,} \beta(s), \beta(y \mid v) \text { is a perfect Bayesian equilibrium. }
\end{gathered}
$$

The individual rationality constraint of the bank (4) indicates that in the case of a payment lower than payment $R_{1}$ required by the credit agreement, the bank in the worst case is assured of the expected liquidation value of the loan. Condition (5) imposes a requirement on the voluntary payment $v$ to be larger than the return $y$ and not to exceed $R_{1}$. 
Proposition 1. If the triplet $\left(I, R_{1}, C\right)$ is the credit agreement signed at time $t=0$, then the solution of Problem 1 is the following perfect Bayesian equilibrium in which

1. The strategy of the borrower is:

$$
v(y)=\left\{\begin{array}{cccc}
0 & \text { for } & y<\frac{b C+\bar{u}}{1-a}, \\
a y+b C+\bar{u} & \text { for } & \frac{b C+\bar{u}}{1-a} & \leq y<\frac{R_{1}-b C-\bar{u}}{a}, \\
R_{1} & \text { for } & y & \geq \frac{R_{1}-b C-\bar{u}}{a},
\end{array}\right.
$$

2. The updated belief of the bank is:

$$
\beta(y \mid v)=\left\{\begin{array}{ccc}
y<\frac{b C+\bar{u}}{1-a} & \text { for } & v<\frac{b C+\bar{u}}{1-a}, \\
y=\frac{v-b C-\bar{u}}{a} & \text { for } & R_{1}>v \geq \frac{b C+\bar{u}}{1-a}, \\
y \geq \frac{R_{1}-b C-\bar{u}}{a} & \text { for } & v \geq R_{1},
\end{array}\right.
$$

3. The strategy of the bank is:

$$
\sigma_{B}(v)=\left\{\begin{array}{l}
0 \quad \text { for } \quad v<\frac{b C+\bar{u}}{1-a} \\
1 \text { for } \quad v \geq \frac{b C+\bar{u}}{1-a}
\end{array}\right.
$$

Proof. The proof will be carried out in three steps.

i) Consider a borrower who makes repayments $v<(b C+\bar{u}) /(1-a)$. In this case we have

$$
\forall_{v<(b C+\bar{u}) /(1-a)} v<a v+b C+\bar{u} \leq a y+b C+\bar{u}=L(y),
$$

hence the repayment of $v$ is less than the liquidation value of the loan $L(y)$ for each $y<(b C+\bar{u}) /(1-a)$. No matter how much the borrower will repay, the bank will obtain a higher amount of the liquidation of the loan, therefore the bank would prefer to liquidate the loan than to carry out a restructuring. 
An updated bank's belief of the borrower's type after observing the payment $v$ will be

$$
\beta\left(y<\frac{b C+\bar{u}}{1-a} \mid v\right)=1
$$

since for each $y \geq(b C+\bar{u}) /(1-a)$ there is $y \geq a y+b C+\bar{u}=L(y)$. The borrower of such return on the project could repay $v(y)=L(y)$ to avoid liquidation and maintain collateral $C$.

For each $v<(b C+\bar{u}) /(1-a)$ the liquidation value of the loan $L(y)$ at belief $\beta(y \mid v)$ is greater than $v$, so the bank will liquidate the loan $^{7}$, which satisfies condition (ii) of Definition 2. In accordance with the principle of sequential rationality, the borrower's type $y \geq(b C+\bar{u}) /(1-a)$ will not make payment $v<(b C+\bar{u}) /(1-a)$ anticipating liquidation of the loan and loss of collateral. The borrower's type $y<(b C+\bar{u}) /(1-a)$ makes the lowest possible repayment for equilibrium, that is, $v(y)=0$, which satisfies condition (i) of Definition 2.

Ultimately, the unique perfect Bayesian equilibrium for $y<(b C+\bar{u}) /(1-a)$ is the equilibrium (pooling), in which the borrower pays $v(y)=0$, and the bank uses a strategy $\sigma_{B}(v)=0$.

ii) Consider a borrower $y^{\prime}$, such that $y^{\prime}=(b C+\bar{u}) /(1-a)$ and any type of borrower $y^{\prime \prime}$ such that $(b C+\bar{u}) /(1-a)<y^{\prime \prime}<\left(R_{1}-b C-\bar{u}\right) / a$, where $y^{\prime \prime}=y^{\prime}+\delta, \delta>0$.

Suppose the borrower $y^{\prime}$ will pay $v^{\prime}=y^{\prime}=a y^{\prime}+b C+\bar{u}=L\left(y^{\prime}\right)$. The bank will accept this payment with a positive probability, as a result of the liquidation he/she will not receive a higher value. The borrower with positive probability will retain collateral $C$. It is, therefore, the optimal strategy for the borrower $y^{\prime}$, because any other payment will give him/her payoff $-C$.

\footnotetext{
${ }^{7}$ In fact, at any belief $\beta\left(y \mid v<\frac{b C+\bar{u}}{1-a}\right)>0$ the liquidation value of the loan is $L(y)>v$.
} 
Suppose the borrower type $y$, such that $y^{\prime}<y \leq y^{\prime \prime}$, pretends a lower return and proposes repayment $v\left(y^{\prime \prime}\right)=v^{\prime}$, expecting the restructuring of the loan and the acquisition of surplus $a\left(y-y^{\prime}\right)$. The bank, foreseeing the possibility of fraud, updates its belief after observing payment $v^{\prime}$ to $\beta\left(y^{\prime}<y \leq y^{\prime \prime} \mid v^{\prime}\right)>0$. The difference between the expected liquidation value of the loan $E L(y)$ and the repayment of $v$ ' with such belief of the borrower's type will be

$$
\begin{aligned}
\forall_{\delta>0} E\left[L\left(y \mid y^{\prime}<y \leq y^{\prime \prime}\right)-v^{\prime}\right] & =\int_{y^{\prime}}^{y^{\prime \prime}} \beta\left(y \mid v^{\prime}\right)\left(a y+b C+\bar{u}-v^{\prime}\right) d y= \\
& =a \int_{y^{\prime}}^{y^{\prime}+\delta} \beta\left(y \mid v^{\prime}\right)\left(y-y^{\prime}\right) d y>0 .
\end{aligned}
$$

The repayment proposed by borrowers is therefore lower than the expected liquidation value. The bank does not carry out debt restructuring. There can be no pooling equilibrium.

Assume that all borrowers of the type $y$ such that $y^{\prime} \leq y \leq y^{\prime \prime}$ repay $v(y)=a y+b C+\bar{u}$. Repayment shall be equal to the liquidation value of each type. The updated belief of the bank in such a strategy of the borrower is

$$
\beta\left(y=\frac{v-b C-\bar{u}}{a} \mid v\right)=1
$$

hence, the bank agrees to restructure its debt as it does not get a higher payoff as a result of the liquidation of the loan, which satisfies condition (ii) of Definition 2. The borrower gains from restructuring $\Delta=(1-a) y-b C-\bar{u} \geq 0$, which is the optimal strategy, as making any other payment he/she gets lower income. That is, paying off the amount $v(y)>L(y)$ higher than his/her liquidation value he/she gets a smaller surplus than $\Delta$. In turn, if the debt was paid below its liquidation value, it would result in a change of the bank's belief of $\beta(y \mid v)$, a liquidation of the loan with positive probability and the payoff to the entrepreneur equal to $-C<0$. Therefore condition (i) of Definition 2 is satisfied.

Consider further the borrower's type $y^{\prime \prime \prime}$, such that $y^{\prime \prime}<y^{\prime \prime \prime}<\left(R_{1}-b C-\bar{u}\right) / a$, where $y^{\prime \prime \prime}=y^{\prime \prime}+\varepsilon$ and $\varepsilon>0$. It has been shown 
that the optimal strategy for the borrower's type $y^{\prime \prime}$ in equilibrium is payment equal to $L\left(y^{\prime \prime}\right)$. Suppose that it is beneficial for borrower $y^{\prime \prime \prime}$ to change the strategy and to pay an amount other than his/her liquidation value. Analogous to the reasoning for the types of $y^{\prime}<y \leq y^{\prime \prime}$, one can show that the optimal strategy for the types of $y^{\prime \prime}<y \leq y^{\prime \prime}$ is a repayment equal to its liquidation value $L(y)$, which is a contradiction. Thus, all the borrower's types $y$ such that $y^{\prime}<y \leq y^{\prime \prime \prime}$ will pay off $v(y)=a y+b C+\bar{u}$.

Ultimately, the unique perfect Bayesian equilibrium ${ }^{8}$ for $y$ satisfying $(b C+\bar{u}) /(1-a) \leq y<\left(R_{1}-b C-\bar{u}\right) / a$ is equilibrium (separating) in which the borrower repays $v(y)=a y+b C+\bar{u}=L(y)$ and the bank uses a strategy $\sigma_{B}(v)=1$.

iii) It has been shown previously that each borrower's type $y$, for which $(b C+\bar{u}) /(1-a) \leq y<\left(R_{1}-b C-\bar{u}\right) / a$, paying off the equivalent of the liquidation value $L(y)$ is the optimal strategy. Suppose that borrower $y \geq\left(R_{1}-b C-\bar{u}\right) / a$ makes a payment equal to its liquidation value $L(y)$. It can be proved similarly to (ii) that in the absence of a fixed amount of repayment $R_{1}$, this would be the optimal strategy.

If $y \geq\left(R_{1}-b C-\bar{u}\right) / a$, an excess return $y$ over the liquidation value $L(y)$ satisfies

$$
\forall_{y \geq\left(R_{1}-b C-\bar{u}\right) / a} y-L(y)=(1-a) y-b C-\bar{u} \leq(1-a) y+a y-R_{1}=y-R_{1} .
$$

Any borrower for whom the return $y \geq\left(R_{1}-b C-\bar{u}\right) / a$, would therefore prefer to pay a fixed amount $R_{1}$ rather than an amount equal to its liquidation value, as it provides him/her not less than the repayment of the liquidation value $L(y)$. The bank under the credit agreement must accept the payment of $R_{1}$. Hence, the payment $R_{1}$ is the optimal strategy for type $y \geq\left(R_{1}-b C-\bar{u}\right) / a$, which satisfies condition (i) of Definition 2.

The updated bank's belief of the borrower's type after observing the payment $R_{1}$ is

\footnotetext{
${ }^{8}$ The equilibrium becomes unique after meeting the criteria of refinement defined by Cho and Kreps (1987), the borrower pays the lowest amount possible for an equilibrium - it is also a requirement for the optimum solution of the problem.
} 


$$
\beta\left(y \geq \frac{R_{1}-b C-\bar{u}}{a} \mid R_{1}\right)=1 .
$$

The unique perfect Bayesian equilibrium for $y \geq\left(R_{1}-b C-\bar{u}\right) / a$ is the equilibrium (pooling), in which the borrower pays $v(y)=R_{1}$, and the bank uses a strategy $\sigma_{B}(v)=1$

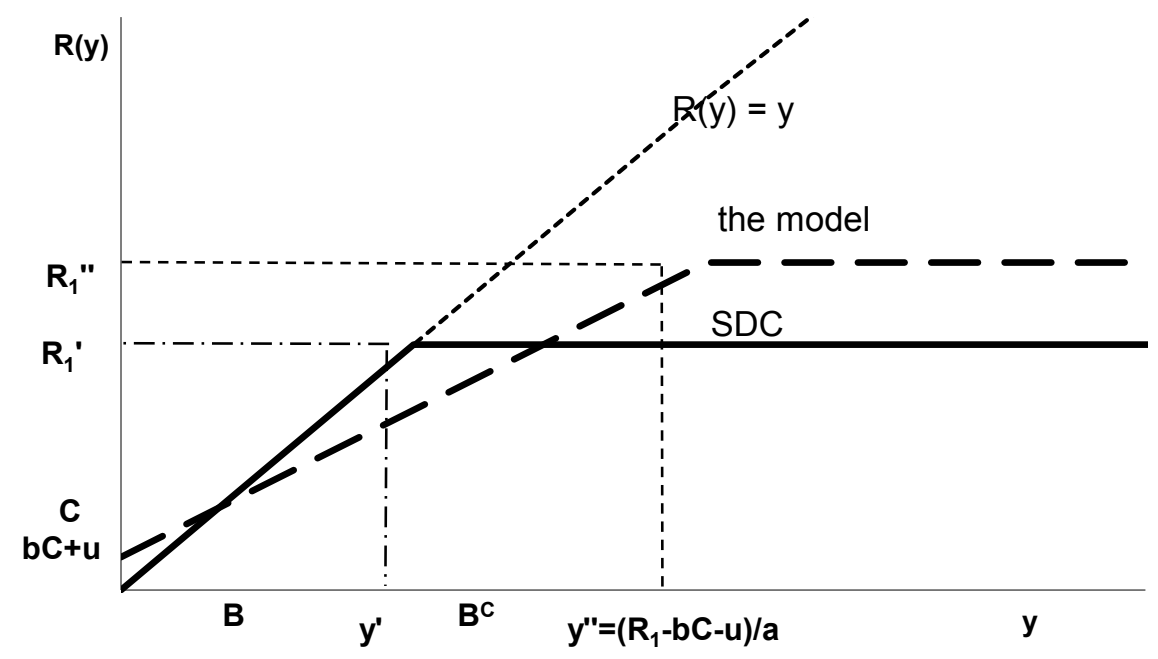

Figure 2. The difference in payments between the standard debt contract (SDC) and our model taking into account the possibility of debt restructuring

Source: author's own.

Proposition 1 shows an interesting observation that the bank is able to assess the type of the borrower for project returns $(b C+\bar{u}) /(1-a) \leq$ $y<\left(R_{1}-b C-\bar{u}\right) / a$, which is a revelation mechanism (see Myerson 1979), but the lack of the bank's credible threat makes it impossible to force a higher payment than the equivalence of the liquidation value.

Repayment of the loan on the basis of Proposition 1 resembles the standard debt contract. Figure 2 shows a diagram of loan repayment from the bank's point of view, due to Proposition 1, in comparison with the standard debt contract (SDC). The difference in the function of payment in relation to the standard debt contract is mainly due to the informal debt renegotiation out of court at no cost, due to the pledge of collateral on assets owned by the 
borrower prior to the credit agreement and due to the ability of the costless falsification of project returns (see Lacker and Weinberg 1989).

The possibility of renegotiation of the bank loan leads to a loss of income of the bank in the area of default $B$ (to the left of the point $y^{\prime}$ ). What is more, for the initial part of the repayment area $B^{C}$ (the complement of the set $B$ ) the borrower will force strategic restructuring, causing further loss of the bank's payoff. As a result, the bank signing the credit agreement at time $t=0$ and anticipating the borrower's strategy has to impose a higher amount of $R_{1}$, which means a higher loan interest rate to cover additional losses resulting from potential debt restructuring.

Any non-monetary value of the reputation of the borrower, which could be supplemented by the objective function (3) of the optimization problem, does not affect the equilibrium specified in Proposition 1. The reputation of the debtor can at best affect indirectly the reduction of the reservation value $\bar{u}$ of a bank, making it more attractive to carry out debt restructuring.

\section{INTEREST RATE IN THE CREDIT AGREEMENT}

Let us assume from now the bank and the entrepreneur intend to write a credit agreement. At time $t=0$, the entrepreneur applying for the loan in the amount of $I$ has to solve the following optimization problem.

Problem 2. At time $t=0$, find the $R_{1}, v, s_{B}$ solving the following program

subject to

$$
\max _{R_{1}, v, \sigma_{B}} E \pi_{E}\left(R_{1}, y, v, \sigma_{B}\right)
$$

$$
\begin{gathered}
\int_{y \in Y} \beta(y)\left[\sigma_{B} v+\left(1-\sigma_{B}\right)(a y+b C+\bar{u})\right] d y-I\left(1+r_{B}\right) \geq 0 \\
0 \leq v \leq y \text { and } v \leq R_{1} \text { for each } y \\
v, \sigma_{B} \text { is the solution of Problem } 1 \\
E \pi_{E}\left(R_{1}, y, v, \sigma_{B}\right) \geq u_{E}
\end{gathered}
$$

The individual rationality constraint of the bank (8) states that the expected value of credit transactions for the bank should be non-negative. No condition imposing consistence in time (see e.g. Krasa and Vilamill 2000), assumes a non-cooperative approach to solve the problem. The borrower, after observing project outcome at the period $t=1$, has no 
incentive at $t=2$ to act in accordance with the credit agreement signed at time $t=0$, which expresses the condition (10). The individual rationality constraint of the entrepreneur (11) forces the expected value of project outcome, taking into account the credit agreement, to be not less than the reservation value of the entrepreneur $u_{E}$.

Proposition 2. Suppose the triplet $\left(I, R_{1}, C\right)$ is the credit agreement for fixed I and $C$ and condition (11) holds. The solution of Problem 2 is payment $R_{1}$ satisfying the equation

$$
\int_{0}^{\frac{1}{a}\left(R_{1}-b C-\bar{u}\right)}(a y+b C+\bar{u}) f(y) d y+R_{1} \int_{\frac{1}{a}\left(R_{1}-b C-\bar{u}\right)}^{\bar{y}} f(y) d y-I\left(1+r_{B}\right)=0 .
$$

Proof. Starting from condition (10), the expected income of the bank at time $t=3$, according to proposition 1 , includes for $y<\frac{1}{a}\left(R_{1}-b C-\bar{u}\right)$ the sum of the expected liquidation value in the case of default and the expected repayment of the loan as a result of the restructuring, which are together equal to the expected liquidation value of the loan $E L(y)$, and for $y \geq \frac{1}{a}\left(R_{1}-b C-\bar{u}\right)$ includes the repayment $R_{1}$ promised in the credit agreement. The expected value of the bank's income is therefore

$$
E \pi_{B}=\int_{0}^{\frac{1}{a}\left(R_{1}-b C-\bar{u}\right)}(a y+b C+\bar{u}) \beta(y) d y+R_{1} \int_{\frac{1}{a}\left(R_{1}-b C-\bar{u}\right)}^{\bar{y}} \beta(y) d y .
$$

For condition (8) at $t=0$, it is necessary that the expected value of the loan contract determined by (13) is not less than the amount of the loan plus the cost of raising capital by the bank. After taking into account the fact that belief $\beta(y)$ has density $f(y)$ and bringing the expected value of credit transactions in a competitive market to zero, we get the equality (12).

Rearranging (12) we obtain

$$
\begin{aligned}
& a \int_{0}^{\frac{1}{a}\left(R_{1}-b C-\bar{u}\right)} y d F(y)+b C F\left(\frac{R_{1}-b C-\bar{u}}{a}\right)+ \\
& +R_{1}\left[1-F\left(\frac{R_{1}-b C-\bar{u}}{a}\right)\right]-I\left(1+r_{B}\right)=0
\end{aligned}
$$

where $R_{1}=I(1+r)$ and $r$ is the loan interest rate. 
For any borrower, the value of the expected revenue of the bank on the basis of equation (14) will depend on the amount of repayment $R_{1}$, the value of collateral $C$ and the distribution of project returns $F$. The bank, setting the amount of the repayment $R_{1}$, before granting a loan, must take into account the value of collateral and consequently its impact on the liquidation value and on the payment resulting from debt renegotiation. They should also take into account the likelihood of liquidation, restructuring and repayment, as well as the expected value of their payments for these events depending on the distribution of project returns. According to the assumption of the model, for any type of borrower the expected return on the project depends only on the distribution. The dependence of the amount of the loan repayment, including the loan interest rate, on the value of the collateral, on the distribution and on the expected return on the project is shown by lemmas 1-3.

Lemma 1. The loan interest rate is a decreasing and convex function of the value of collateral.

Proof. Let us take equation (14) as implicit function $E \pi_{B}\left(R_{1}, C, F\right)=0$ (subject to the assumptions of the implicit function theorem). Differentiating successively with respect to $C$ and $R_{1}$, we obtain

$$
\begin{aligned}
\frac{\partial E \pi_{B}}{\partial C}= & \frac{b}{a} R_{1} f\left(\frac{R_{1}-b C-\bar{u}}{a}\right)-b \frac{R_{1}-b C}{a} f\left(\frac{R_{1}-b C-\bar{u}}{a}\right)+ \\
& +b F\left(\frac{R_{1}-b C-\bar{u}}{a}\right)-\frac{b^{2}}{a} C f\left(\frac{R_{1}-b C-\bar{u}}{a}\right) .
\end{aligned}
$$

After this transformation, and taking into account the assumption $C \leq R_{1}$ we have

$$
\frac{\partial E \pi_{B}}{\partial C}=b F\left(\frac{R_{1}-b C-\bar{u}}{a}\right)>0 .
$$

Then

$$
\begin{aligned}
\frac{\partial E \pi_{B}}{\partial R_{1}}= & 1+\frac{R_{1}-b C}{a} f\left(\frac{R_{1}-b C-\bar{u}}{a}\right)-F\left(\frac{R_{1}-b C-\bar{u}}{a}\right)+ \\
& +\frac{b}{a} C f\left(\frac{R_{1}-b C-\bar{u}}{a}\right)-\frac{1}{a} R_{1} f\left(\frac{R_{1}-b C-\bar{u}}{a}\right),
\end{aligned}
$$


whence we obtain

$$
\frac{\partial E \pi_{B}}{\partial R_{1}}=1-F\left(\frac{R_{1}-b C-\bar{u}}{a}\right)>0 .
$$

Finally,

$$
\frac{\partial R_{1}}{\partial C}=-\frac{b F\left(\frac{R_{1}-b C-\bar{u}}{a}\right)}{1-F\left(\frac{R_{1}-b C-\bar{u}}{a}\right)}<0 .
$$

Hence, the amount of the loan repayment $R_{1}$ is a decreasing function of collateral. Then calculating the second derivative we obtain finally

$$
\frac{\partial^{2} R_{1}}{\partial C^{2}}=\frac{b^{2} f\left(\frac{R_{1}-b C-\bar{u}}{a}\right)}{a\left[1-F\left(\frac{R_{1}-b C-\bar{u}}{a}\right)\right]^{3}}>0 .
$$

The amount of loan repayment $R_{1}$ is therefore a convex function of the value of collateral $C$.

Since the interest rate $r=R_{1} / I-1>0$ is proportional to the amount of the repayment $R_{1}$, both the first and second derivatives retain their signs. Thus the interest rate is decreasing and convex function of collateral $C$.

Let us assume that the distribution of the borrower's return on the project is a conditional distribution function $F(y \mid \omega)$, where $\omega \in \mathbb{R}_{+}$is a measure of risk, which may be, for example, the credit risk assessment carried out by the bank. A detailed review, usually in points, allows banks to assign borrowers the appropriate group of credit risk. This assessment may be an explicit measure of risk. If, however, higher rating points mean a lower credit risk then one would need to make a reverse scaling. Assume further that the distribution function $F$ has a first-order stochastic dominance with respect to $\omega$, that is, for a fixed $y$ we have $F\left(y \mid \omega^{\prime}\right)<F\left(y \mid \omega^{\prime \prime}\right)$ for $\omega^{\prime}<\omega^{\prime \prime}$, where the higher the value of $\omega$ indicates a higher level of credit risk. Thus, the expected return meets the inverse relationship $E Y\left(\omega^{\prime}\right)>E Y\left(\omega^{\prime \prime}\right)$. In addition, the assumptions of continuity and differentiability of $F(\cdot \cdot)$ in respect to $y$ are valid, also we assume the existence of a continuous derivative of $F(\cdot \cdot)$ with respect to $\omega$. 
Lemma 2. The loan interest rate is an increasing function of the borrower's risk measure $\omega$.

Proof. Let us present (14), using the rule of integration by parts, as

$$
\begin{gathered}
\left(R_{1}-b C-\bar{u}\right) F\left(\frac{R_{1}-b c-\bar{u}}{a} \mid \omega\right)-a \int_{0}^{\frac{1}{a}\left(R_{1}-b C-\bar{u}\right)} F(y \mid \omega) d y+ \\
+b C F_{\omega}\left(\frac{R_{1}-b C-\bar{u}}{a} \mid \omega\right)+R_{1}\left[1-F_{\omega}\left(\frac{R_{1}-b C-\bar{u}}{a} \mid \omega\right)\right]-I\left(1+r_{B}\right)=0 .
\end{gathered}
$$

After reducing and differentiating the above expression with respect to $\omega$ we have

$$
\frac{\partial E \pi_{B}}{\partial \omega}=-\bar{u} F_{\omega}\left(\frac{R_{1}-b c-\bar{u}}{a} \mid \omega\right)-a \int_{0}^{\frac{1}{a}\left(R_{1}-b C-\bar{u}\right)} F_{\omega}(y \mid \omega) d y<0,
$$

where $F_{\omega}(\cdot \cdot)$ is the first derivative of $F(\cdot \mid \cdot)$ with respect to $\omega$, which, under the assumption of stochastic dominance is positive. Taking into account formula (15), we obtain

$$
\frac{\partial R_{1}}{\partial \omega}=\frac{\bar{u} F_{\omega}\left(\frac{R_{1}-b c-\bar{u}}{a} \mid \omega\right)+a \int_{0}^{\frac{1}{a}\left(R_{1}-b C-\bar{u}\right)} F_{\omega}(y \mid \omega) d y}{1-F\left(\frac{R_{1}-b C-\bar{u}}{a}\right)}>0 .
$$

The amount of loan repayment $R_{1}$, and thus the interest rate directly proportional to it, are an increasing function of credit risk measures $\omega$.

Lemma 3. The loan interest rate is a decreasing function of the expected return on borrower's project $E Y$.

Proof. Let we express the repayment amount $R_{1}$ as $R_{1}=g(\omega)$, where $g: \mathbb{R}_{+} \rightarrow \mathbb{R}_{+}$, wherein $g$ from Lemma 2 is an increasing function of $\omega$. Let us express the value of the expected return on the project as $E Y=h(\omega)$, where $h: \mathbb{R}_{+} \rightarrow \mathbb{R}_{+}$. Under the assumption of stochastic dominance of conditional distribution function $F(\cdot \mid \cdot)$ it follows that $h$ is decreasing. The function $h$ is invertible, so we have $\omega=h^{-1}(E Y)$, and the inverse is also decreasing. Let us take the submission of $R_{1}=g^{\circ} h^{-1}(E Y)$, which is a decreasing function of the expected value $E Y$, since for all $x_{1}<x_{2}$ belonging 
to the domain of $h$ we have $h^{-1}\left(x_{1}\right)>h^{-1}\left(x_{2}\right)$, and $g\left(h^{-1}\left(x_{1}\right)\right)>g\left(h^{-1}\left(x_{2}\right)\right)$. As a result the interest rate, as directly proportional to $R_{1}$, is a decreasing function of the expected value $E Y$.

Lemmas 1 and 3 show that the dependence of the loan rate on the total value of collateral and on the expected return on the project, contingent upon the level of credit risk, is decreasing. This leads to the following conclusion.

Corollary 1. The loan interest rate determined by the bank at the time of writing the agreement is a decreasing function of the expected liquidation value $E L=a E Y+b C+\bar{u}$.

Empirical studies confirm the impact of the liquidation value of borrowers' assets on interest rates, as well as the amounts and the maturity of credit agreements and on the results of debt renegotiations. These findings are included in the research of John et al. (2003), Benmelech et al. (2005), Benmelech and Bergman (2008 and 2009), and Franks and Sussman (2005). The more general research of Kędzior (2012) shows the relation between tangible fixed assets and long term indebtedness in European countries. Corollary 1 is clearly supported by the empirical studies of Polish companies conducted by Paliński (2012 and 2013). These studies show the strong correlation between loan interest rates and the estimated liquidation value of borrowers' assets, according to the absence of the relation with the capitalization of companies.

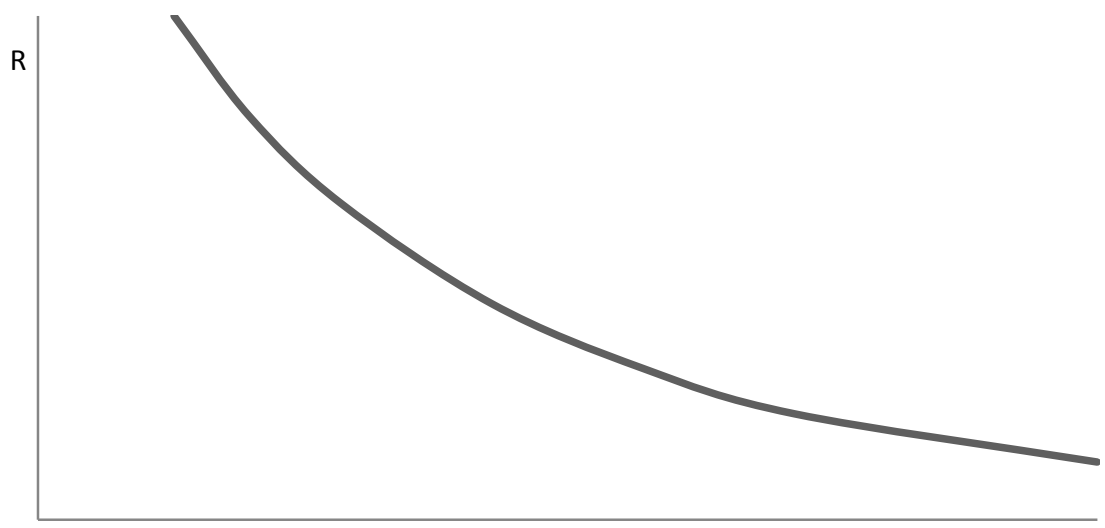

$\mathrm{EL}$

Figure 3. Dependence of loan repayment amount on the expected liquidation value EL Source: author's own. 
An example of the relationship between the payment amount specified in the loan contract and the expected liquidation value of a loan is shown in Figure 3. Based on Lemmas 1 and 3 and the fact that the value of assets of typical enterprises is much higher than the return on project (ROA is usually a few percent), it can be assumed that in practice the loan interest rate dependence on the liquidation value is not only non-linear, but also convex.

\section{A NUMERIC EXAMPLE OF PRICING A LOAN WITH THE USE OF THE MONTE CARLO METHOD}

The model presented in this work, like most theoretical models, is a simplification of reality, otherwise it would be impossible to solve analytically. An increase of realism of the model is possible by the adoption of the numerical approach and the Monte Carlo simulation techniques. The numerical approach allows, for example, to include in the model, the variability of assets of a borrower and their correlation with project returns and the business cycle (see Niniimaki 2011). A weaker return on the project is usually associated with poor economic conditions in the industrial sector and makes a debtor's assets less attractive to other businesses. It is also possible to make dependent the coefficients $a$ and $b$ on the financial condition of the borrower. Economic underperformance of the entrepreneur causes moral hazard and concealment of assets, and favours the takeover of assets by other creditors.

The idea of the Monte Carlo method consists in generating the $i=1,2, . ., k n$-dimensional independent random variables $Z_{i}$ with the same distribution $F(z)$ representing the $k$ stochastic inputs in a model, and using them to the $n$-fold deterministic model calculations. As a result of this procedure, distribution of random output variable can be found (e.g. profit, return, price of financial instrument, etc.). Random variable $Z_{i}$ is obtained by means of pseudo-random number generator (or quasi-random) with uniform distribution in $[0,1]^{k}$ and the method of "reverse distribution", i.e. $Z=F^{-1}(U)$, where $U$ is a random variable with uniform distribution $U \sim$ Unif $[0,1]^{k}$. The error of the Monte Carlo estimator is proportional to $n^{-1 / 2}$. In the case of multivariate normal distribution $Z \sim N(\mu, \Sigma)$ with the variance-covariance matrix $\Sigma$, the decompositions: Cholesky, eigenvalues or singular values can be used to obtain the relationship between random variables (see more: Glasserman 2004, Jackel 2002). 
The game theoretic approach to the loan repayment, presented in this paper, can be used practically to determine the interest rate on a loan. The determination of the loan interest rate in the simulation model is carried out according to (12). The model is particularly suitable for the valuation of large investment loans where a borrower with the loan application must provide a risk analysis of a project that contains the probability distributions of the risk factors of the project. For smaller investments banks can use the empirical distributions resulting from the historical data.

A loan interest rate $r$ is determined so that the present value (NPV) of the bank's cash flows during the credit agreement discounted at $r_{B}=r_{d}+r_{m}$, being the sum of the cost of raising capital $r_{d}$ and margin to cover operating costs $r_{m}$, is zero. This is explained in the following formula:

$$
N P V=\sum_{t=0}^{T} \frac{-I_{t}+p_{t}+i_{t}+L_{t}}{\left(1+r_{B}\right)^{t}}=0
$$

and

$$
i_{t}=D_{t}(1+r)
$$

where:

$I_{t}-$ tranches of the loan,

$p_{t}$ - repayment of principal,

$i_{t}$ - interest payments and fees,

$L_{t}$ - the liquidation value of the assets,

$r_{B}$ - the discount rate,

$D_{t}-$ credit debt in period $t$,

$T$ - number of periods to expire the loan,

$r$ - searched loan interest rate.

The periodicity should correspond to the payments of instalments (month, quarter, year). The interest rate and the discount rate may be reduced to the effective annual rates taking into account the compounded interest. Random variables in the model are: the cost of raising funds (deposits, equity, interbank market), the premium to cover the operating costs of the bank, the cash flows generated by the borrower's investment project in subsequent periods, the value of the borrower's assets owned before the credit agreement used to secure the payment $C$, the rate of recovery of previously owned assets $b$, the rate of recovery of assets resulting from the project $a$, the reservation value $\bar{u}$. Moreover, the random variables $a$ and $b$ can be multidimensional random variables $a=\left(a_{1}, a_{2}, \ldots, a_{q}\right), b=\left(b_{1}, b_{2}, \ldots b_{p}\right)$, in 
which dimensions of the random variables $q$ and $p$ represents the number of different classes of assets belonging to the debtor's wealth.

In the simplified model the following assumptions were used. The investment project lasts three years. In the first year the project is under construction. The project generates cash flows only in the second and third years of the $C F_{i}$, where $i=2,3$. The investment loan of $I=1,000$ is paid in one tranche on the last day of year 0 . The grace period for repayment of the principal is one year. The principal amount is repaid in equal annual instalments on the last day of year 2 and year 3. In the absence of full payment of the second instalment, the unpaid principal and interests increases the debt at the beginning of the third year. In a more general case, it could be assumed that in such a solution the bank can accept this only when the expected value of future payments exceeds the liquidation value. In the absence of full repayment of the loan, the bank seizes the borrower's assets at their liquidation value at the end of the third year.

Random variables in the model:

- the cash flow of the project in the second year of $C F_{2} \sim N(800,400)-$ investment projects usually do not reach full capacity at the beginning of the run,

- the cash flow of the project in the third year of $C F_{3} \sim N(1200,600)$, correlated with $\mathrm{CF}_{2}$, and the correlation coefficient $\rho_{\mathrm{CF}_{2}, \mathrm{CF}_{3}}=0.7$ - initial success or failure of the project significantly affect its future financial performance,

- $a \sim N(0.4,0.1)$, correlated with $C F_{3}$, and the correlation coefficient $\rho_{a, C F_{3}}=0.7-$ even though we did not introduce into the model an explicit variable representing the business cycle, it is assumed that the liquidation value of the assets depends on the economic performance of the firm by making them more valuable in favourable economic conditions, while the low return on the project leading to the bad financial condition of the debtor increases the risk of acquisition of assets by other creditors,

- $b \sim N(0.4,0.1)$, correlated with $C F_{3}$, and the correlation coefficient $r_{b, C F_{3}}=0.5$ - analogous to the relationship of a coefficient, but having a weaker correlation with project outcome, as it relates to assets previously owned by the entrepreneur,

- $\bar{u} \sim N(0,100)$, correlated with $C F_{i}$, and the correlation coefficient $\rho_{\bar{u}, C F_{2}}=-0.8$, and with $C F_{3}$, and the correlation coefficient $\rho_{\bar{u}, C F_{3}}=-0.9$ 
- a strong negative correlation means that in the case of a high return on the project, seizing the assets and bringing the entrepreneur into bankruptcy would cost the bank the loss of the benefits of further cooperation with the company,

- the cost of raising capital $r_{d} \sim N(4.0 \%, 1.0 \%)$ is the same throughout the life of the loan.

The margin to cover operating costs was set as fixed of $r_{m}=2 \%$. The value of the borrower's assets held before the start of the project have also been adopted as fixed value. It was depreciated at an $10 \%$ annual rate and changed in the decision analysis in the range of 1,000 to 4,000 with increments of 500 .

The adoption of realistic assumptions regarding the coefficients $a$ and $b$ as the dependent variables on the project returns makes the function of the repayment of the loan non-linear and convex in the area of default in Figure 1 between the points $(0, b C+\bar{u})$ and $\left(\left(R_{1}-b C-\bar{u}\right) / a, R_{1}^{\prime \prime}\right)$, thus making the result of the numerical model even more different than the standard debt contract of our theoretical model as shown in Figure 4.

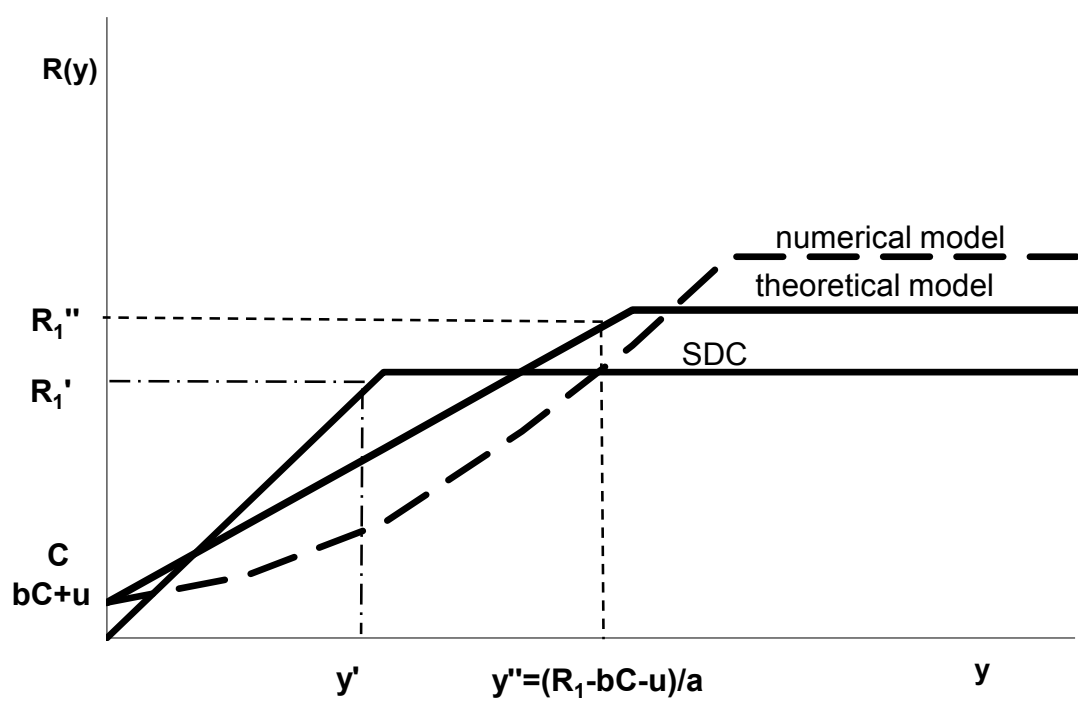

Figure 4. The difference in payments between the standard debt contract (SDC) and our numerical and theoretical models

Source: author's own. 
Instead of many random variables representing the cash flows and assets value of the borrower, or the cost of funding in subsequent periods, in a large number of periods (e.g. monthly) the random variable describing the transition between following periods can be entered. This process can be modelled as a random growth or random walk process (see Siarka 2012).

The main assumptions of the model calculation are shown in Table 1. The Monte Carlo simulation was performed using the Oracle ${ }^{\circledR}$ Crystal Ball for 50,000 simulation runs. The loan rate $r$ is obtained by an iterative approach by repeatedly zooming up to meet equation (16). The simulation results are included in Table 2 and depicted in Figure 5. The numerical results look very similar to the theoretical line presented in Figure 3.

Table 1

Assumptions of the numerical model

\begin{tabular}{l|r|r|r|r}
\hline \multirow{2}{*}{ Parameter } & \multicolumn{3}{c}{ Years } \\
\cline { 2 - 5 } & \multicolumn{1}{c|}{$\mathbf{0}$} & \multicolumn{1}{c}{$\mathbf{1}$} & \multicolumn{1}{c}{$\mathbf{2}$} & \multicolumn{1}{c}{$\mathbf{3}$} \\
\hline Interest rate $\boldsymbol{r}$ (decision variable) & $\mathbf{7 . 2 6 \%}$ & & & \\
\hline The rate of depreciation (yearly) & $10.00 \%$ & & & \\
\hline The cost of funding $r_{d}$ & $4.00 \%$ & & & \\
\hline The required rate of return $r_{B}$ & $6.00 \%$ & & & \\
\hline Tranche & $-1,000.0$ & & & 500.0 \\
\hline The amount of debt & & $1,000.0$ & $1,000.0$ & 500.0 \\
\hline Yearly principal payment & & & 500.0 & 36.3 \\
\hline Yearly interest payment & & 72.6 & 72.6 & $1,399.2$ \\
\hline The value of assets of the project & $2,000.0$ & $1,727.4$ & $1,554.7$ & 800.0 \\
\hline Cash flow & & & 227.4 & $1,200.0$ \\
\hline Cumulative retained cash flows & & & & 891.1 \\
\hline Reservation value $\bar{u}$ & & & 0.5 & 0.0 \\
\hline Recovery parameter $a$ & & & 0.4 & 0.5 \\
\hline Recovery parameter $b$ & & & 1021.9 & $1,273.4$ \\
\hline The liquidation value (before & & & $\mathbf{5 7 2 . 6}$ & $\mathbf{5 3 6 . 3}$ \\
payment of principal ad interests) & & & & \\
\hline Cash flows of the bank & $-\mathbf{1 , 0 0 0 . 0}$ & $\mathbf{7 2 . 6}$ & & \\
\hline
\end{tabular}

Note: shaded cells indicate random variables

Source: author's calculations.

The simulation results indicate that, having equal profitability and risk of the project, profitability of the loan depends largely on the value of collateral (assets owned by the borrower) at the date of signing the credit agreement. This relationship is particularly strong when not taking into account the bank's reservation value $\bar{u}$. The correlation of the reservation value with the 
project returns means that with a good financial standing of the borrower, the bank receives the benefits of further cooperation with him/her. On the other hand, in the case of poor financial results, the borrower, fearing the tendency of seizing collateral by the bank, uses most of the cash flow to repay the debt.

Table 2

Simulation results of the loan rate dependence on the initial value of the borrower's assets

\begin{tabular}{|c|c|c|}
\hline \multirow[b]{2}{*}{$\begin{array}{l}\text { The initial value } \\
\text { of the borrower's assets }\end{array}$} & \multicolumn{2}{|c|}{ Interest rate } \\
\hline & $\begin{array}{l}\text { Without the reservation } \\
\text { value of the bank } \\
\text { [basis point] }\end{array}$ & $\begin{array}{l}\text { With the reservation } \\
\text { value of the bank } \\
\text { [basis point] }\end{array}$ \\
\hline 1,000 & 982 & 865 \\
\hline 1,500 & 878 & 780 \\
\hline 2,000 & 794 & 726 \\
\hline 2,500 & 731 & 681 \\
\hline 3,000 & 701 & 643 \\
\hline 3,500 & 681 & 623 \\
\hline 4,000 & 664 & 615 \\
\hline
\end{tabular}

Note: one basis point is one-hundredth of a percentage point.

Source: author's calculations.

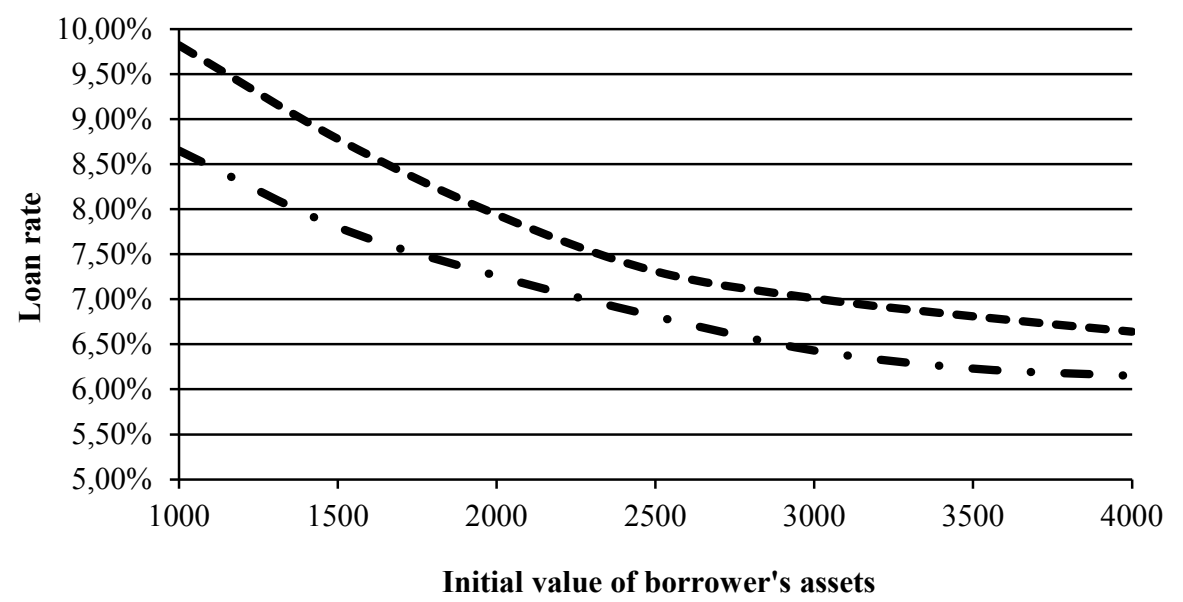

- - without reservation utility - - with reservation utility

Figure 5. The relation of the loan rate to the initial value of the borrower's assets in the numerical example

Source: author's calculations. 
It was assumed that the expected rate of return on the loan required by the bank is 600 basis points, while the interest rate on the loan which the bank must charge the borrower to provide the required expected rate of return varies between 615 b.p. and 982 b.p.

\section{CONCLUSION}

The analysis of the model presented in this paper shows that under asymmetric information a borrower is willing to reach for renegotiation and cancellation of debt to a greater extent than is required by the return on a project financed by a loan. An important finding of the model is to draw attention to the key role of the liquidation value in the bank's lending activities. In equilibrium a borrower pays the lesser of: the amount equal to the liquidation value of the loan or the amount of payment specified in the credit agreement. The profit of the bank under the credit agreement is always the smaller of the two values

$$
\pi_{B}=\min \left\{L, R_{1}\right\}
$$

where:

$\pi_{B}$ - bank's profit from the credit agreement,

$L$ - the liquidation value of loan,

$R_{1}$ - repayment amount specified in the credit agreement.

If the borrower does not repay the debt according to the agreement, the bank, with no credible threat to bring enforcement or bankruptcy of the debtor, is forced to accept the proposed payment of not less than the liquidation value. To offset the impact of possible renegotiation, the amount of the loan payment specified in the credit agreement must take into account ex ante the liquidation value.

Credit risk reduction therefore requires to adjust not only the interest rate but also the amount of credit to the liquidation value of borrowers' assets. A similar view on imposing lending limits in relation to the value of the collateral was presented by Griffith-Jones, Ocampo and Ortiz (2009). More general conclusions of our model can be as follows:

1. banks should adjust exposure of individual credit transaction to the forecasted liquidation value of loan,

2. financial supervisory authorities should monitor the credit exposure of banks in relation to the liquidation value, 
3. state authorities should monitor the credit activities of banks in relation to the value of tangible assets to avoid credit bubbles.

The results of our model are consistent to some extent with the assumptions of the Moody's KMV structural credit risk management model, and generally Merton's model (1974), in which the loan is treated as a put option on the assets of the company. The difference is that the gametheoretic model proposed in this paper utilises the concept of the liquidation value of loan, which takes into account the cost of acquisition of the borrower's assets by the bank. In addition, due to the possibility of loan renegotiating, the bank's profit is reduced in comparison with the amount required to repay in the original credit agreement, like in Hvide and Lite (2010), where default does not mean bankruptcy. Another difference is the fact that the liquidation value of the loan is a broader concept than a borrower's assets, and additionally, includes the present value of the potential future earnings of the debtor and the bank's share in it.

The numeric example included in this paper depicts how the gametheoretic model can be used to price credit with the utilisation of the Monte Carlo methods. The numerical example clearly confirms the relationship between the return on the loan and the liquidation value of the borrower's assets. The game-theoretic model using the liquidation value may be a good alternative to option pricing models, especially for the risk management of bank loans.

\section{REFERENCES}

Aghion, P., Bolton, P., An Incomplete Contracts Approach to Financial Contracting, "Review of Economic Studies", Vol. 59, No 3, pp. 473-494, 1992.

Attar, A, Campioni, E., Costly State Verification and Debt Contracts: A Critical Resume, "Research in Economics", Vol. 57, pp. 315-343, 2003.

Barro, R., The Loan Market, Collateral, and Rates of Interest, "Journal of Money, Credit and Banking", Vol. 8, No 4, pp. 439-456, 1976.

Benmelech, E., Bergman, N., Liquidation Values and the Credibility of Financial Contract Renegotiation: Evidence from U.S. Airlines, "Quarterly Journal of Economics", No 123, pp. 1635-77, 2008.

Benmelech, E., Bergman, N., Collateral Pricing, "Journal of Financial Economics", No 91, pp. 339-60, 2009.

Benmelech, E., Garmaise, M., Moskowitz, T., Do Liquidation Values Affect Financial Contracts? Evidence from Commercial Loan Contracts and Zoning Regulation, "Quarterly Journal of Economics", Vol. 120, pp. 1121-54, 2005.

Besanko, D., Thakor, A., Collateral and Rationing: Sorting Equilibria in Monopolistic and Competitive Credit Markets. "International Economic Review", Vol. 28, No 3, pp. 671$-689,1987$. 
Bester, H., Screening vs. Rationing in Credit Markets with Imperfect Information, "The American Economic Review", Vol. 75, No 4, pp. 850-855, 1985.

Bester, H., The Role of Collateral in a Model of Debt Renegotiation, "Journal of Money, Credit and Banking", Vol. 26, No 1, pp. 72-86, 1994.

Bharath, S., Dahiya, S., Saunders, A., Srinivasan, A., So What Do I get? The Bank's View of Lending Relationships, "Journal of Financial Economics", Vol. 85, pp. 368-419, 2007.

Bolton, P., Scharfstein, D., Optimal Debt Structure and the Number of Creditors, "The Journal of Political Economy", Vol. 104, No 1, pp. 1-25, 1996.

Boot, A., Relationship Banking: What Do We Know?, "Journal of Financial Intermediation", No 9, pp. 7-25, 2000.

Carlier, G., Renou, L., A Costly State Verification Model with Diversity of Options, "Economic Theory", Vol. 25, pp. 497-504, 2005.

Cho, I., Kreps, D., Signaling Games and Stable Equilibria, "The Quarterly Journal of Economics", Vol. 102, No 2, pp. 179-222, 1987.

Coco, G., On the Use of Collateral, "Journal of Economic Surveys", Vol. 14, No 2, pp. 191$-214,2000$.

Davydenko, S., When Do Firms Default? A Study of the Default Boundary. Available at SSRN: http://ssrn.com/abstract=672343, 2012.

Degryse, H., Relationship Lending within a Bank-Based System: Evidence from European Small Business Data, "Journal of Financial Intermediation”, Vol. 9, pp. 90-109, 2000.

Franks, J. R., Sussman, O., Financial Distress and Bank Restructuring of Small to Medium Size UK Companies, "The Review of Finance", Vol. 9, No 1, pp. 65-96, 2005.

Gale, D., Hellwig, M., Incentive-compatible Debt Contracts, The One-Period Problem. "The Review of Economics Studies", Vol. 52, pp. 647-663, 1985.

Gilson, S., John, K., Lang, L., Troubled Debt Restructurings: An Empirical Study of Private Reorganization of Firms in Default, "Journal of Financial Economics", No 26, pp. 315$-53,1990$.

Glasserman, P., Monte Carlo Methods in Financial Engineering. Springer-Verlag, New York, Berlin, Heidelberg, 2004.

Gorton, G., Kahn, J., The Design of Bank Loan Contracts, "Review of Financial Studies", No 13, pp. 331-364, 2000.

Griffith-Jones, S., Ocampo J., Ortiz A., Building on the Counter-cyclical Consensus: A Policy Agenda, Foundation for European Progressive Studies, 2009.

Hart, O., Moore, J., A Theory of Debt Based on the Inalienability of Human Capital, "The Quarterly Journal of Economics", Vol. 109, No 4, pp. 841-879, 1994.

Hart, O., Moore, J., Default and Renegotiation: A Dynamic Model of Debt, "The Quarterly Journal of Economics", Vol. 113, No 1, pp. 1-41, 1998.

Hvide, H., Leite, T., Optimal Debt Contracts under Costly Enforcement, "Economic Theory", Vol. 44, pp. 149-165, 2010.

Jackel, P., Monte Carlo Methods in Finance. John Wiley \& Sons, Chichester, 2002.

John, K., Lynch, A., Puri, M., Credit Ratings, Collateral, and Loan Characteristics: Implications for Yield, "Journal of Business", Vol. 76, pp. 371-409, 2003. 
Kędzior, M., Capital Structure in EU Selected Countries - Micro And Macro Determinants, "Argumenta Oeconomica", Vol. 28, No 1, 2012, pp. 69-117.

Krasa, S., Villamil, A., Optimal Contracts when Enforcement is a Decision Variable, "Econometrica", Vol. 68, No 1, pp. 119-134, 2000.

Krasa, S., Sharma, T., Villamil, A., Debt Contracts and Cooperative Improvements, "Journal of Mathematical Economics", Vol. 41, pp. 857-874, 2005.

Lacker, J., Collateralized Debt as the Optimal Contract, "Review of Economic Design", Vol. 4, pp. 842-859, 2001.

Lacker, J., Weinberg, J., Optimal Contracts under Costly State Falsification, "The Journal of Political Economy", Vol. 97, pp. 1345-1363, 1989.

Merton, R., On the Pricing of Corporate Debt: The Risk Structure of Interest Rates, "The Journal of Finance", Vol. 29, pp. 449-470, 1974.

Myerson, R., Incentive Compatibility and the Bargaining Problem, "Econometrica", Vol. 47, No 1, pp. 61-73, 1979.

Niinimaki, J., Nominal and True Cost of Loan Collateral, "Journal of Banking and Finance", Vol. 35, pp. 2782-2790, 2011.

Paliński, A., The Liquidation Value and Bank Loan Valuation - Evidence from Polish Corporations, "Journal on Legal and Economic Issues of Central Europe", Vol. 3, No 3, pp. 54-61, 2012.

Paliński, A., Wpływ wartości likwidacyjnej aktywów firmy na oprocentowanie kredytu bankowego - wyniki badań polskich spółek giełdowych [The Impact of Assets' Liquidation Value of an Enterprise on Loan Rate - Evidence from Polish Corporations], "Bank and Credit", Vol. 44, No 2, pp. 207-236, 2013.

Petersen, M., Rajan, R., The Benefits of Lending Relationships: Evidence from Small Business Data, "Journal of Finance", Vol. 49, pp. 3-37, 1994.

Rajan, R., Insiders and Outsiders: The Choice between Informed and Arm's Length Debt, "Journal of Finance", Vol. 47, pp. 1367-1400, 1992.

Roberts, M., Sufi, A., Renegotiation of Financial Contracts: Evidence from Private Credit Agreements, "Journal of Financial Economics", No 93, pp. 159-84, 2009.

Siarka, P., Symulacyjna analiza rentowności kredytów detalicznych. Testowanie warunków skrajnych [Simulation Analysis of Profitability of Retail Loans. Stress Testing], "Bank and Credit", Vol. 43, No 2, pp. 81-104, 2012.

Thakor, A., Wilson, P., Capital Requirements, Loan Renegotiation and The Borrower's Choice of Financing Source. "Journal of Banking \& Finance", Vol. 19, pp. 693-711, 1995.

Received: May 2014, revised: July 2017 